also how it couples with other materials' features (including adhesion, optical and electric properties, and so on). Additionally, the potential interest of this finding at larger scales remains to be addressed, as it is unclear how the lattice defects, grain boundaries or other crystal imperfections, which would naturally arise in macroscale contacts, would affect the tribology performance of this heterojunction. Nevertheless, the potential technological implications of the findings from Song and co-workers establish an important step. At the micrometre-scale alone, translational and rotational superlubric motion would certainly benefit the over US $\$ 18$ billion market of the microelectromechanical systems.

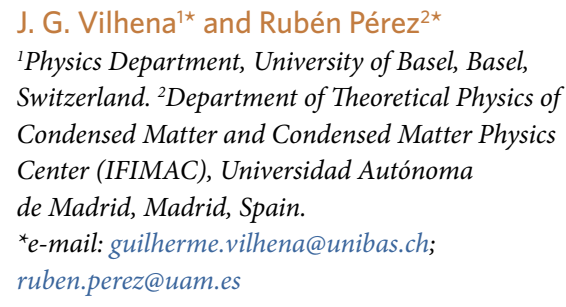

Published online: 24 September 2018 https://doi.org/10.1038/s41563-018-0172-8
References

1. Holmberg, K., Andersson, K. \& Erdemir, A. Tribol. Int. 47, 221-234 (2012).

2. Song, Y. et al. Nat. Mater. https://doi.org/10.1038/s41563-0180144-Z (2018).

3. Hirano, M. \& Shinjo, K. Wear 168, 121-125 (1993).

4. Erdemir, A. \& Martin, J. M. Superlubricity (Elsevier, Amsterdam, 2007).

5. Martin, J. M., Donnet, C. Le Mogne, Th. \& Epicier, Th. Phys. Rev. B. 48, 10583-10586 (1993).

6. Dienwiebel, M. et al. Phys. Rev. Lett. 92, 126101 (2004).

7. Martin, J. M. \& Erdemir, A. Phys. Today 71, 40-46 (April, 2018).

8. Liu, Z. et al. Phys. Rev. Lett. 108, 205503 (2012).

9. Koren, E., Lörtscher, E., Rawlings, C., Knoll, A. W. \& Duerig, U. Science 348, 679-683 (2015).

10. Berman, D., Deshmukh, S. A., Sankaranarayanan, S. K. R. S., Erdemir, A. \& Sumant, A. V. Science 348, 1118-1122 (2015).

11. Eryilmaz, O. L. \& Erdemir, A. Surf. Coat. Technol. 203 750-755 (2008)

12. Fontaine, J., Donnet, C., Grill, A. \& Le Mogne, T. Surf. Coat. Technol. 286, 146-147 (2001).

\title{
Moonage daydreams of space rock
}

T he moon landing by Apollo 11, which will be widely celebrated on its 50th anniversary next year, seemed at least to settle that hoary old question of what material the moon is made of. In all, the Apollo astronauts brought back around $380 \mathrm{~kg}$ of the satellite - rocks and regolith - for chemical and mineralogical analysis: one of the few (literally) tangible scientific benefits of the Apollo programme. (NASA, however, had to admit several years ago that many 'astromaterials' had been lost from its collection, including many of the Apollo lunar rock samples, mostly misplaced following loans to researchers and educators.)

Surprisingly, though, these materials have still not produced a consensus about the composition of the moon. Even now, half a century later, studies of physical samples and remote measurements from spacecraft are yielding conflicting conclusions about the lunar fabric. Just last year, Milliken and Li reported ${ }^{1}$ that spectra of lunar pyroclastic (volcanicderived) deposits, widespread on the lunar surface, taken by the Indian Space Research Organisation's Chandrayaan-1 lunar probe suggest that these materials, which originated deep within the moon's interior, have a high water content. That was consistent with water-rich volcanic glassy grains found in Apollo samples ${ }^{2}$, and implied that those materials weren't anomalies but may reflect the general composition of the lunar interior. This in turn cast doubt on the common view that the moon's geological fabric is depleted in volatile substances such as water.

The implications of water-rich moon rocks are profound. Media reports spoke excitedly of potential sources of water for future moon bases, but the more immediate issue concerns the moon's formation. If, as was widely suspected, it was created from material torn off the young Earth in a collision with a planet-sized object dubbed Theia in the early solar system, then the violence of that event might have been expected to deplete the debris of volatiles. So whence the water? Did it somehow remain with the terrestrial material that formed to moon? Or was it delivered soon after by comets? Or is the impact hypothesis wrong?

Modern analyses of moon rocks, benefitting from the precision of today's techniques, are still informing and changing this story. Wang and Jacobsen, for example, recently showed $^{3}$ that the lunar samples are enriched in heavy isotopes of potassium relative to the Earth, which they explain by invoking a much more catastrophic impact than previously considered, more or less vaporizing the colliding bodies.

As for that water: the jury is not in yet. A new analysis ${ }^{4}$ of one of the Apollo 16 samples brought back in 1972 - which has plenty

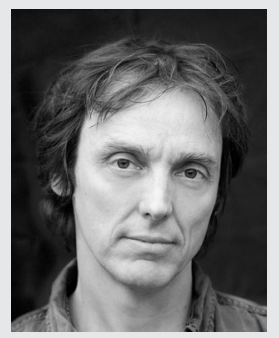

Philip Ball

of volatiles - shows that its zincisotope composition is what one would expect from a material that had been boiled dry by volcanism. The authors suggest that the interior of the moon is dry after all, while surface materials like the Apollo volcanic glasses became hydrated by condensation of expelled volatiles.

It seems unlikely that we have heard the last word. The stories we tell about the moon seem acutely dependent on how sensitively we can probe the materials that, nearly 50 years ago, we began to bring back from it.

Published online: 24 September 2018 https://doi.org/10.1038/s41563-018-0181-7

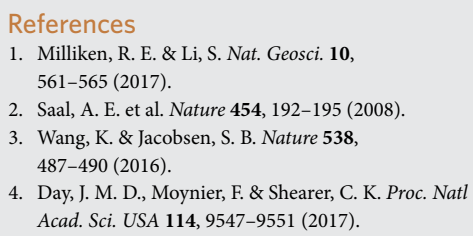

